\title{
Adsorption of antibiotics on microplastics ${ }^{\text {h }}$
}

\author{
Jia Li ${ }^{\text {a, b}}$, Kaina Zhang ${ }^{\text {c }}$, Hua Zhang a, * \\ ${ }^{a}$ Key Laboratory of Coastal Environmental Process and Ecology Remediation, Yantai Institute of Coastal Zone Research, Chinese Academy of Sciences, Yantai \\ 264003, China \\ ${ }^{\mathrm{b}}$ University of Chinese Academy of Sciences, Beijing 100049, China \\ c School of Environment and Materials Engineering, YanTai University, Yantai 264003, China
}

\section{A R T I C L E I N F O}

\section{Article history:}

Received 31 October 2017

Received in revised form

31 January 2018

Accepted 16 February 2018

Available online 15 March 2018

\section{Keywords:}

Antibiotics

Microplastics

Adsorption

Distribution coefficient

\begin{abstract}
A B S T R A C T
Microplastics and antibiotics are two classes of emerging contaminants with proposed negative impacts to aqueous ecosystems. Adsorption of antibiotics on microplastics may result in their long-range transport and may cause compound combination effects. In this study, we investigated the adsorption of 5 antibiotics [sulfadiazine (SDZ), amoxicillin (AMX), tetracycline (TC), ciprofloxacin (CIP), and trimethoprim (TMP)] on 5 types of microplastics [polyethylene (PE), polystyrene (PS), polypropylene (PP), polyamide (PA), and polyvinyl chloride (PVC)] in the freshwater and seawater systems. Scanning Electron Microscope (SEM) and X-ray diffractometer (XRD) analysis revealed that microplastics have different surface characterizes and various degrees of crystalline. Adsorption isotherms demonstrated that PA had the strongest adsorption capacity for antibiotics with distribution coefficient $\left(K_{d}\right)$ values ranged from $7.36 \pm 0.257$ to $756 \pm 48.0 \mathrm{~L} \mathrm{~kg}^{-1}$ in the freshwater system, which can be attributed to its porous structure and hydrogen bonding. Relatively low adsorption capacity was observed on other four microplastics. The adsorption amounts of 5 antibiotics on PS, PE, PP, and PVC decreased in the order of $\mathrm{CIP}>\mathrm{AMX}>\mathrm{TMP}>\mathrm{SDZ}>\mathrm{TC}$ with $K_{f}$ correlated positively with octanol-water partition coefficients (Log $\mathrm{K}_{\mathrm{ow}}$ ). Comparing to freshwater system, adsorption capacity in seawater decreased significantly and no adsorption was observed for CIP and AMX. Our results indicated that commonly observed polyamide particles can serve as a carrier of antibiotics in the aquatic environment.
\end{abstract}

(C) 2018 Elsevier Ltd. All rights reserved.

\section{Introduction}

During the last 60 years, plastic production increased considerably from around 0.5 million tonnes in 1950 to 311 million tonnes in 2014 (Thompson et al., 2009; Plastics, 2015), which accompanied by increasing release of plastic waste to the environment. It is estimated that 4.8-12.7 million tonnes of plastic waste washed offshore in 2010 alone (Jambeck et al., 2015). Recently, microplastics (MPs) with particle size in the micrometer range have become the focus of study due to their potential toxic impact to aquatic ecosystems. MPs have been detected in surface water (Zhao et al., 2015), water column (Nel and Froneman, 2015), and bottom sediments (Browne et al., 2011). Previous studies have showed that polyethylene (PE), polystyrene (PS), polypropylene (PP), polyamide (PA), and polyvinyl chloride (PVC) are the most frequently detected

\footnotetext{
This paper has been recommended for acceptance by Maria Cristina Fossi.

* Corresponding author.

E-mail address: hzhang@yic.ac.cn (H. Zhang).
}

MPs in the aquatic environment (Hidalgo-Ruz et al., 2012; Fok et al., 2017). It is believed that MPs can accumulate various toxins and chemical pollutants and serve as a carrier for long-range transport (Guo et al., 2012; Turner and Holmes, 2015; Hueffer and Hofmann, 2016).

Studies have been conducted on the adsorption behaviors of organic pollutants or heavy metals onto different types of MPs (Bakir et al., 2014a, 2014b, Velzeboer et al., 2014; Wang et al., 2015; Hueffer and Hofmann, 2016; Wu et al., 2016) as well as the effects of plastic types and environmental factors (e.g., ionic strength and $\mathrm{pH}$ ) on pollutants adsorption processes (Wang et al., 2015). Both the sorbent and the sorbate properties can influence the adsorption extent significantly. For instance, properties of MPs such as polarity, abundance of rubbery, and degree of crystalline have great impacts on adsorption capacities of pollutants (Guo et al., 2012; Wang et al., 2015; Brennecke et al., 2016). The hydrophobicity of organic contaminants is also important in determining their adsorption on MPs (Hueffer and Hofmann, 2016). Furthermore, adsorption of organic pollutants on MPs varied in the seawater and the freshwater (Velzeboer et al., 2014), which may be due to the impacts of salinity. 
As reported by Wang et al. (2015), perfluorooctanesulfonate (PFOS) adsorption on PE and PS increased with increasing of ionic strength, while ionic strength had no effect on perfluorooctanesulfonamide (FOSA) adsorption.

As a class of emerging contaminants, antibiotics have received increasing attention due to their impacts on the microbial community as well as the generation of resistance genes (Le et al., 2005; Yang et al., 2017). A large number of antibiotics are released into the environment every year. As evaluated by Zhang et al. (2015), only in China, 53,800 tonnes of antibiotics discharged into the receiving environment in 2013. Studies reported that tetracyclines, macrolides, fluoroquinolones, and sulfonamides are the frequently detected antibiotics in the aquatic environment worldwide (Kolpin et al., 2002; Watkinson et al., 2009; Jiang et al., 2011; Li et al., 2012). Antibiotics such as trimethoprim, fluoroquinolones, and sulfonamides were found to be stable in surface water (Lunestad et al., 1995; Lin et al., 2010). More importantly, the residual antibiotics may pose relatively high ecological risk to the relevant aquatic organisms (Xu et al., 2013). If antibiotics can be absorbed by MPs, both could have higher toxic effects on aquatic life due to the combined pollution. There is evidence that persistent organic pollutants (POPs) can transfer from MPs to Artemia nauplii and further to zebrafish via a trophic food web (Batel et al., 2016). Thus, understanding the possible reactions between different kinds of antibiotics and MPs is warranted for the evaluation of their environmental risks.

The physicochemical properties such as specific surface area, degree of crystallinity, and pore size distribution vary substantially among different types of microplastic particles and may dominate their antibiotics adsorption capacities. To verify this hypothesis, experiments were conducted 1) to describe the structures and properties of 5 MPs using analytical techniques such as Scanning Electron Microscope (SEM) and X-ray diffractometer (XRD); 2) to evaluate the adsorption capacities of 5 types of commonly used antibiotics in the freshwater and seawater systems.

\section{Materials and method}

\subsection{Chemicals}

Sulfadiazine (SDZ), amoxicillin (AMX), tetracycline (TC), ciprofloxacin (CIP), and trimethoprim (TMP) were purchased from Sigma-Aldrich (USA), with $>99 \%$ purity. The physicochemical properties of antibiotics was shown in Table S1. Acetonitrile were high-performance liquid chromatography (HPLC) grade and were obtained from Anaqua Chemicals Supply (ACS, USA). Ultrapure water (MQ) was obtained from a Milli-Q water purification system (Millipore, Billerica, MA, USA). The other reagents were analytical grade or higher. Seawater was filtered through $0.45 \mu \mathrm{m}$ membranes and irradiated with ultraviolet light to eliminate the influences of dissolved organic matter as much as possible. TC, AMX, and TMP were dissolved in the background solutions (i.e. ultrapure water and filtered seawater) directly to prepare the stock solutions. For SDZ and CIP, methanol was added to enhance their solubility in background solutions. All the stock solutions were kept in the dark at $4{ }^{\circ} \mathrm{C}$ for no long than one week. Stock solutions were diluted to the desired concentrations before use.

\subsection{Microplastic particles and analytical methods}

Polyethylene (PE), polystyrene (PS), polypropylene (PP), polyamide (PA), and polyvinyl chloride (PVC) were purchased as powders from Youngling Electromechanical Technology Co., Ltd. (Shanghai, China). The physicochemical properties of 5 MPs were shown in Table S2. The particle sizes distribution of these polymers were shown in Fig. S1. For any kinds of MPs, more than $90 \%$ of polymers fell into the $75-180 \mu \mathrm{m}$ size classes. Their point of zero charge (PZC) were analyzed based on the method described by Ferro-Garcia et al. (1998). The polymers microscopic morphological characteristics were analyzed by a Scanning Electron Microscope (SEM) (S-4800, Hitachi, Japan). The crystalline compositions of MPs were measured using X-ray diffractometer (XRD) (XRD-7000, SHIMADZU, Japan) with a $\mathrm{Cu}-\mathrm{K} \alpha$ as the radiation source $(\lambda=1.5406 \AA)$. The samples were scanned over the range of $5-90^{\circ}$ of $2 \theta$ at a rate of $1^{\circ} \mathrm{min}^{-1}$.

\subsection{Batch adsorption experiments}

Batch adsorption experiments for 5 antibiotics were undertaken with 5 concentration gradients (i.e. $0.5,1,5,10$, and $15 \mathrm{mg} \mathrm{L}^{-1}$ ) at room temperature $\left(25^{\circ} \mathrm{C}\right)$. Specifically, $0.02 \mathrm{~g}$ of each plastic particle was added into the glass vials. Different volumes of background solution (ultrapure water or filtered seawater) were added according to the concentration gradient. Then, antibiotic stock solution with a concentration of $50 \mathrm{mg} \mathrm{L}^{-1}$ was added to make up the suspension volume of $5 \mathrm{~mL}$ in each glass vial capped with a Teflon gasket. To minimize the effects of cosolvent, the volume ratio of methanol in the test solution was controlled below $0.1 \%$. The glass vials were shaken in a temperature-controlled shaking incubator (HZS-HA, Harbin, China) at a shaking speed of $180 \mathrm{rpm}$ at $25^{\circ} \mathrm{C}$ for $4 \mathrm{~d}$. After equilibrium, the sample was filtered through a $0.22 \mu \mathrm{m}$ syringe filter before analysis. All the adsorption experiments were conducted in triplicate. The blank sorption experiments with the reactor system containing antibiotics without MPs were carried out. The loss of antibiotics during sorption test was calculated and subtracted from the blank loss. To improve calculation accuracy, the amounts of antibiotics adsorbed on MPs were calculated using the following equation:

$q_{e}=\frac{\frac{m_{2}-m_{1}}{\rho_{2}}\left(c_{0}-c_{e}\right)-\frac{m_{1}-m_{0}}{\rho_{1}} c_{e}-\alpha}{m}$

where $q_{\mathrm{e}}\left(\mathrm{mg} \cdot \mathrm{g}^{-1}\right)$ is the equilibrium adsorption amount; $c_{0}$ and $c_{\mathrm{e}}$ $\left(\mathrm{mg} \cdot \mathrm{L}^{-1}\right)$ are the initial concentration and the equilibrium concentration; $\rho_{1}$ and $\rho_{2}\left(\mathrm{~g} \mathrm{~mL}^{-1}\right)$ are density of the background solution and the antibiotic stock solution, respectively; $m(\mathrm{~g})$ is the mass of adsorbent; $m_{0}(\mathrm{~g})$ is the mass of the adsorbent and the vial; $m_{1}(\mathrm{~g})$ is the mass after adding the background solution; $m_{2}(\mathrm{~g})$ is the mass after adding the antibiotic stock solution; $\alpha(\mathrm{mg})$ is blank loss.

\subsection{Adsorption model}

Linear, Freundlich, and Langmuir adsorption models were used to fit the adsorption isotherms of antibiotics. Briefly, the Linear model can be described as:

$q=K_{d} C_{e}$

where $q\left(\mathrm{mg} \mathrm{g}^{-1}\right)$ is the absorbed amount of antibiotic; $C_{e}\left(\mathrm{mg} \mathrm{L}^{-1}\right)$ is antibiotic mass in the aqueous phase at equilibrium the equilibrium; and $K_{d}\left(\mathrm{~L} \mathrm{~g}^{-1}\right)$ is the partition coefficient. The Freundlich model is given by:

$q=K_{f} C_{e}^{n}$

where $K_{f}\left(\mathrm{~L} \mathrm{~g}^{-1}\right)$ is the Freundlich adsorption coefficient which indicates adsorption capacity; $n$ is the Freundlich isotherm exponent that determines the non-linearity. The Langmuir isotherm model can be expressed as follow: 
$q=q_{\max } \frac{k_{L} C_{e}}{1+k_{L} C_{e}}$

where $q_{\max }\left(\mathrm{mg} \mathrm{g}^{-1}\right)$ represents the maximum adsorption capacity; $K_{L}\left(\mathrm{~L} \mathrm{mg}^{-1}\right)$ is related proportionally to the affinity between plastic particles and antibiotics.

\subsection{Detection of antibiotics}

All the selected antibiotics were detected using highperformance liquid chromatography (Exformma 1600, USA) equipped with a UV detector. Chromatographic separations were performed with a SDS HYPERSIL C18 $(250 \mathrm{~mm} \times 4.6 \mathrm{~mm}, 5 \mu \mathrm{m})$. The column temperature was $30^{\circ} \mathrm{C}$. The flow rate was $1.0 \mathrm{~mL} \mathrm{~min}{ }^{-1}$ and injection volume was $50 \mu \mathrm{L}$. The mobile phase and detection wavelength varied across antibiotics and were shown in Table 1. The detection limit of 5 antibiotics ranged from 0.01 to $0.05 \mathrm{mg} \mathrm{L}^{-1}$, and the relative standard deviation (RSD) of antibiotic measurements was less than 3.0\%. For each kind of antibiotics, two standard curves (one for ultrapure water and another for seawater) with seven-point (i.e. $0.1,0.5,1,5,10,15,20 \mathrm{mg} \mathrm{L}^{-1}$ ) were used for quantitative analysis. The $\mathrm{r}^{2}$ of standard curves were between 0.990 and 1.00 .

\section{Results and discussion}

\subsection{Characterization of MPs}

Fig. 1 shows the SEM micrographs of PE, PVC, PS, PP, and PA, respectively. The surface of PE particle was relatively smooth, while several micropores can be found on the surface of PVC. Reticular formation was developed on the surface of PS particles. Spherical bulges and micropores were observed on the surface and internal cross-section of PP. More importantly, the surface of PA was rough and exhibited characteristics of porous polymer.

The XRD patterns are good indications of the degree of crystalline of plastic particles. Generally, polymer with high degree of crystalline has sharp diffraction peak. As illustrated in Fig. S2, one sharp diffraction peak appeared in the XRD pattern of $\mathrm{PE}$, indicating PE had high degree of crystalline. Similarly, three obvious peaks with high intensity can be found in the XRD pattern of PP. For PS and PA, their diffraction peaks showed the similar intensity. Whereas for PVC, there was no apparent diffraction peak in the $2 \theta$ range of $5-90^{\circ}$. Therefore, the degree of crystallinity followed the order as: $\mathrm{PE}>\mathrm{PP}>\mathrm{PA} \approx \mathrm{PS}>\mathrm{PVC}$.

\subsection{Adsorption isotherms}

Adsorption of antibiotics on MPs in freshwater and seawater were illustrated in Fig. 2. The estimated Linear, Freundlich, and Langmuir parameters were summarized in Table 2 and Table 3. The Freundlich parameter $n$ was related to the non-linearity of isotherms. Previous studies showed that the sorption isotherms of perfluoroalkyl acids (PFAAs), polychlorinated biphenyls (PCBs), and pharmaceuticals and personal care products (PPCPs) on various plastic particles were highly linear (Velzeboer et al., 2014; Wang et al., 2015; Wu et al., 2016). But other study suggested that the linearity of sorption isotherms varied among chemicals and plastic types (Hueffer and Hofmann, 2016). As demonstrated in Tables 2 and 3, the adsorption isotherms of CIP, TMP, and TC on MPs were obviously non-linear with Freundlich $n$ values ranged from 0.303 to 0.842, while adsorption of SDZ and AMX were relatively linear with the larger $n$ values $(n>0.540)$. Correspondingly, the non-linear models (i.e. Freundlich model and Langmuir model) exhibited better goodness-of-fit for isotherms of CIP, TMP, and TC, as indicated by the high values of $r^{2}$. On the contrary, the Linear model was more suitable to simulate the adsorption isotherms of SDZ and AMX. Hueffer and Hofmann (2016) reported that the adsorption of seven non-polar organic compounds by PE, PS, PA, and PVC yielded a better fit with Freundlich model than Langmuir model. However, Bakir et al. (2012) suggested that Langmuir model was more suitable to explain sorption isotherm of bi-sorbates by PE and PVC than Freundlich model. Based on the $\mathrm{r}^{2}$ (Table 2), the adsorption of CIP by PP and PA yielded a better fitness for Langmuir model, while the adsorption of CIP by PS, PE, and PVC yielded a better fitness for Freundlich model. For TMP in the seawater system, Freundlich model was suitable to describe its adsorption on PP, PS, PE, and PA For TMP in the freshwater system, Freundlich model was suitable to describe its adsorption on PA, whereas Langmuir model described its adsorption on PP and PE well. The experiment results indicate that different reaction mechanisms are involved in the adsorption of antibiotics on MPs. More in-depth understanding of the binding mechanisms is required to establish more generalized adsorption model.

\subsection{Effects of microplastic properties}

The adsorption capacities of antibiotics on different MPs varied significantly (Table 2). Physicochemical properties of MPs such as specific surface area, polarity, and degree of crystallinity may affect their adsorption capacities. Wang et al. (2015) suggested that polarity of MPs can influence adsorption levels of polar chemicals. The tested antibiotics are polar compounds (Kanda et al., 2015) and is expected to have strong sorption capacity to polar MPs by the polar-polar interaction. As shown in Table 2, however, only polar PA has significant higher sorption capacity for 4 antibiotics (CIP, TMP, AMX, and TC) in the freshwater system, while polar PVC shows low affinity to polar antibiotics. This indicated that polarity of MPs alone were not capable of explaining the differences in adsorption capacities. As reported by Teuten et al. (2009) and Wang et al. (2015), the rubbery plastic PE showed higher adsorption capacity to organic pollutants than the glassier plastics (i.e. PP, PS, and PVC). However, for any kinds of antibiotics, its sorption capacity on PE was not the largest, which indicating sorption extents of antibiotics had little or no correlation with rubbery state of plastic. Guo et al. (2012) suggested that the plastic with low crystallinity could accumulated more hydrophobic organic pollutants. As shown in section 3.1, the degree of crystallinity of five types of MPs followed the order as: $\mathrm{PE}>\mathrm{PP}>\mathrm{PA} \approx \mathrm{PS}>\mathrm{PVC}$. However, this order was not

Table 1

High-performance liquid chromatography conditions for the analysis of antibiotics.

\begin{tabular}{|c|c|c|c|c|}
\hline Antibiotic & Mobile phase $\mathrm{A}$ & Mobile phase B & Volume radio $(A: B)$ & Wavelength \\
\hline CIP & disodium hydrogen phosphate buffer $(\mathrm{pH}=2.5)$ & acetonitrile & $80: 20$ & $277 \mathrm{~nm}$ \\
\hline SDZ & $0.1 \%$ acetic acid solution & acetonitrile & $78: 22$ & $268 \mathrm{~nm}$ \\
\hline AMO & disodium hydrogen phosphate buffer $(\mathrm{pH}=2.5)$ & acetonitrile & $85: 15$ & $254 \mathrm{~nm}$ \\
\hline TMP & $1 \%$ acetic acid solution & acetonitrile & $80: 20$ & $271 \mathrm{~nm}$ \\
\hline TC & disodium hydrogen phosphate buffer $(\mathrm{pH}=2.5)$ & acetonitrile & $80: 20$ & $360 \mathrm{~nm}$ \\
\hline
\end{tabular}




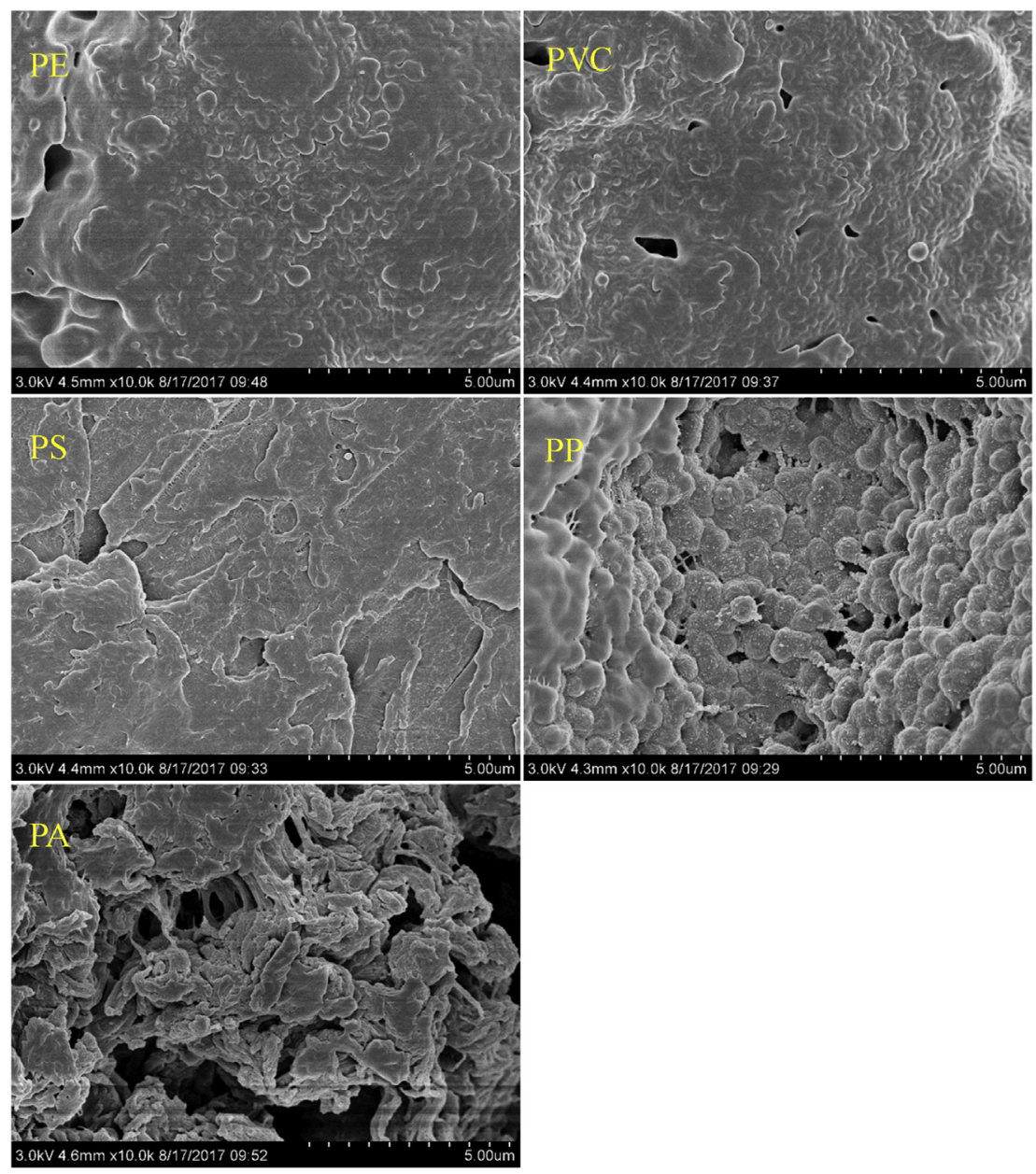

Fig. 1. SEM micrographs of polyethylene (PE), polystyrene (PS), polypropylene (PP), polyamide (PA), and polyvinyl chloride (PVC).

consistent with the order of sorption capacity of any type of antibiotic, indicating the crystallinity of MPs was not the essential factor affecting antibiotic adsorption.

Adsorption capacities of CIP, TMP, and SDZ on PS are higher than those on PE (Table 2). The reason may be that PS can undergo nonspecific vander Waals interactions and $\pi-\pi$ interactions at the aromatic surface, while PE can only undergo the vander Waals interactions (Velzeboer et al., 2014; Hueffer and Hofmann, 2016). As shown in Fig. 1, PS, PP, and especially PA have the developed pore structure, and this may be used to explain why these three MPs have higher sorption capacity than PE and PVC. Furthermore, PA has high adsorption for AMX, TC, and CIP, which can be attributed to the specific functional group (i.e. amide group). Hydrogen bonding can be formed between amide group (proton donor group) of PA and carbonyl group (proton acceptor group) of AMX, TC, and CIP (Antony et al., 2010). Other studies also demonstrated that hydrogen bonding between antibiotics (e.g. TC and CIP) and organic matter (e.g. humic substance and organic carbon) surfaces may contribute to antibiotics sorption (Tolls, 2001; Pils and Laird, 2007). Thus we suggested that the formation of hydrogen bonding as the mechanism underlying the high adsorption of AMX, TC, and CIP on PA.

The properties of MPs exposed to the environment may change because of environmental factors and therefore influence their adsorption behaviors (Turner and Holmes, 2015). For example, the polar functional groups, carbonyl groups, have been identified in aged plastic samples collected from beaches (Zbyszewski and
Corcoran, 2011). The presence of polar functional groups may contribute to the formation of $\mathrm{H}$-bonding. Furthermore, aged plastic particles tend to acquire a greater surface area through photo-oxidation, weathering, and aging (Turner and Holmes, 2011), and this will also favor the adsorption of contaminants.

\subsection{Effects of antibiotic properties}

As shown in Table 2, the adsorption capacities of various antibiotics on a specific type of plastic differed greatly. Apart from PA, adsorption of 5 antibiotics on the other four MPs decreased in the order of CIP $>$ AMX $>$ TMP $>$ SDZ $>$ TC. These results implied that antibiotics properties can influence their adsorptions on MPs. Previous studies indicated that the octanol-water partition coefficients ( $\log K_{\mathrm{ow}}$ ) of sorbates were essential in determining their adsorption extents on MPs (Hueffer and Hofmann, 2016; Wu et al., 2016). That is, the $\log K_{d}$ values of investigated sorbates were positively correlated with their $\log K_{\mathrm{ow}}$ values. The Log $K_{\mathrm{ow}}$ values of the investigated antibiotics decreased in the order of CIP $>$ TMP $>$ AMX $>$ SDZ $>$ TC (Table S1). There was a significantly positive correlation between antibiotics' Log $K_{\text {ow }}$ values and their average $K_{f}$ values on PP, PS, PE, and PVC $(\mathrm{p}<0.05)$. Our results suggested that hydrophobic antibiotics (with higher Log $K_{\mathrm{ow}}$ values) had higher affinity to PP, PS, PE, and PVC. However, this correlation did not apply to PA, indicating hydrophobic interaction was insignificant for antibiotics adsorption on PA.

Antibiotics are ionisable compounds, but the ionization constant 

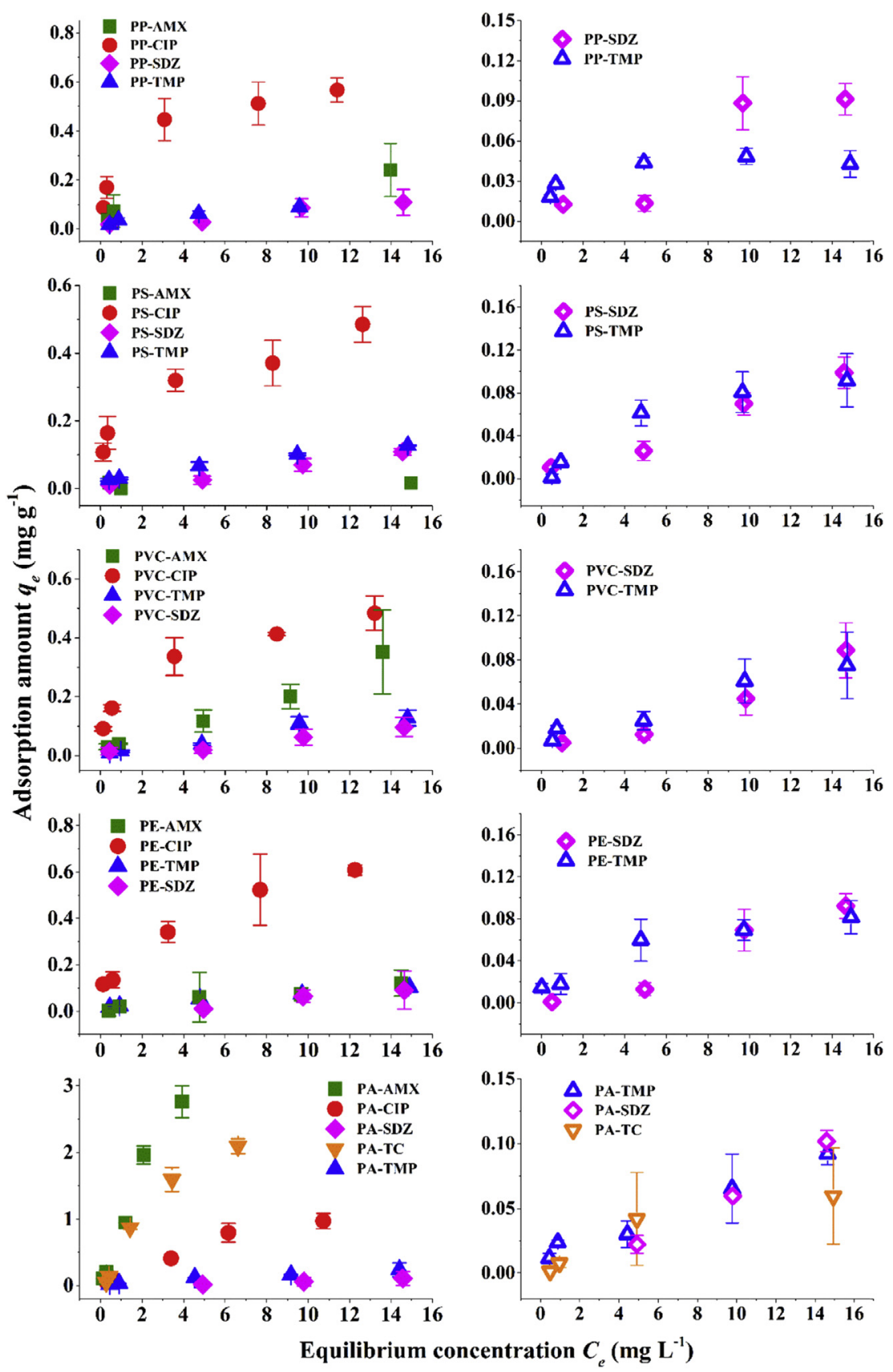

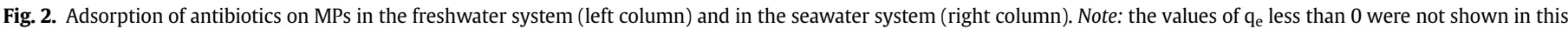
figure.

(pKa) of various antibiotics usually differed significantly because of their specific functional groups. Thus, in a specific $\mathrm{pH}$ condition, various antibiotics will exhibit different speciation of the cation, zwitterion, and anion. The speciation of ionic chemicals can influence their sorption extents on MPs. As reported by Wang et al. (2015), the anionic forms of PFOS showed a higher adsorption capacity on PE with positive surface at low $\mathrm{pH}$ than the nonionic forms of FOSA. The pKa values of 5 antibiotics and their speciation at experimental $\mathrm{pH}$ condition were shown in Table S1. In the freshwater system, all the tested antibiotics were zwitterions and anions; nevertheless, CIP also had a portion of cations. In the seawater system, zwitterions and anions were the main speciation for 5 antibiotics. Because the experimental pH was higher than the PZC of 5 MPs, all the 5 MPs carried a net negative charge. Thus, for
CIP in the freshwater system, the cations of CIP enhanced its sorption capacity on negatively charged MPs surface due to electrostatic attraction.

\subsection{Freshwater and seawater systems}

Our results demonstrated that adsorption of antibiotics on MPs differed among freshwater and seawater systems. As shown in Fig. 2, adsorption of CIP and AMX did not occur in the seawater system. The sorption capacities of TMP, SDZ, and TC also decreased compared with the freshwater system. Differences in ionic strength and $\mathrm{pH}$ values may be used to explain the different sorption capacities in the freshwater and seawater systems. The $\mathrm{pH}$ of seawater system was higher than freshwater system (Table S2); 
Table 2

Estimated Linear, Freundlich, and Langmuir parameters for antibiotics adsorption on MPs in the freshwater system.

\begin{tabular}{|c|c|c|c|c|c|c|c|c|}
\hline \multirow[t]{2}{*}{ MPs } & \multicolumn{2}{|l|}{ Linear } & \multicolumn{3}{|l|}{ Freundlich } & \multicolumn{3}{|l|}{ Langmuir } \\
\hline & $K_{d}\left(\mathbf{L ~ k g}^{-1}\right)$ & $\mathbf{r}^{2}$ & $K_{\boldsymbol{f}}\left(\mathbf{L} \mathbf{k g}^{-1}\right)$ & $n$ & $\mathbf{r}^{2}$ & $q_{\max }\left(\mathrm{mg} \mathrm{g}^{-1}\right)$ & $K_{L}\left(L^{\prime} \mathbf{m g}^{-1}\right)$ & $\mathbf{r}^{2}$ \\
\hline & CIP & & & & & & & \\
\hline PP & $57.1 \pm 11.5$ & 0.827 & $252 \pm 33.3$ & 0.345 & 0.938 & $0.615 \pm 0.0299$ & 0.844 & 0.990 \\
\hline PS & $51.5 \pm 7.76$ & 0.846 & $205 \pm 17.0$ & 0.316 & 0.968 & $0.416 \pm 0.0427$ & 1.67 & 0.903 \\
\hline PVC & $41.5 \pm 7.83$ & 0.844 & $184 \pm 6.19$ & 0.371 & 0.998 & $0.453 \pm 0.00863$ & 1.15 & 0.996 \\
\hline PE & $55.1 \pm 7.94$ & 0.904 & $222 \pm 6.59$ & 0.393 & 0.994 & $0.200 \pm 0.0143$ & 0.443 & 0.990 \\
\hline PA & $\begin{array}{l}96.5 \pm 7.81 \\
\text { TMP }\end{array}$ & 0.968 & $170 \pm 45.2$ & 0.741 & 0.963 & $2.20 \pm 0.657$ & 0.0740 & 0.980 \\
\hline PP & $9.71 \pm 2.28$ & 0.851 & $32.3 \pm 4.01$ & 0.450 & 0.964 & $0.102 \pm 0.0142$ & 0.498 & 0.934 \\
\hline PS & $9.51 \pm 1.07$ & 0.963 & $32.1 \pm 2.48$ & 0.507 & 0.992 & $0.174 \pm 0.0385$ & 0.158 & 0.932 \\
\hline PVC & $8.41 \pm 1.20$ & 0.941 & $13.4 \pm 6.58$ & 0.842 & 0.939 & $0.481 \pm 0.496$ & 0.0259 & 0.944 \\
\hline PE & $8.38 \pm 1.32$ & 0.908 & $22.0 \pm 2.59$ & 0.560 & 0.986 & $0.154 \pm 0.0413$ & 0.116 & 0.939 \\
\hline PA & $\begin{array}{l}17.1 \pm 1.24 \\
\text { SDZ }\end{array}$ & 0.974 & $36.0 \pm 6.15$ & 0.696 & 0.985 & $0.468 \pm 0.128$ & 0.0646 & 0.979 \\
\hline PP & $7.85 \pm 0.679$ & 0.985 & $8.00 \pm 7.14$ & 0.939 & 0.884 & na & na & na \\
\hline PS & $7.39 \pm 0.308$ & 0.995 & $4.10 \pm 2.18$ & 1.22 & 0.972 & na & na & na \\
\hline PVC & $6.61 \pm 0.549$ & 0.973 & $3.20 \pm 2.91$ & 1.27 & 0.918 & na & na & na \\
\hline PE & $6.19 \pm 0.238$ & 0.996 & $2.20 \pm 3.13$ & 1.40 & 0.962 & na & na & na \\
\hline PA & $\begin{array}{l}7.36 \pm 0.257 \\
\text { AMX }\end{array}$ & 0.996 & $1.10 \pm 0.196$ & 1.71 & 0.999 & na & na & na \\
\hline PP & $17.5 \pm 3.39$ & 0.895 & $60.0 \pm 6.55$ & 0.540 & 0.720 & $0.294 \pm 0.0702$ & 0.376 & 0.930 \\
\hline PS & - & - & - & - & - & - & - & - \\
\hline PVC & $24.7 \pm 1.20$ & 0.991 & $20.0 \pm 8.86$ & 1.07 & 0.969 & $0.523 \pm 0.368$ & 0.0657 & 0.953 \\
\hline PE & $8.40 \pm 0.675$ & 0.968 & $18.0 \pm 2.27$ & 0.637 & 0.930 & $0.131 \pm 0.0284$ & 0.174 & 0.920 \\
\hline PA & $\begin{array}{l}756 \pm 48.0 \\
\mathrm{TC}\end{array}$ & 0.980 & $700 \pm 31.8$ & 0.900 & 0.991 & $22.7 \pm 22.6$ & 0.0361 & 0.992 \\
\hline PA & $356 \pm 38.2$ & 0.945 & $588 \pm 128$ & 0.699 & 0.943 & $3.84 \pm 0.839$ & 0.189 & 0.977 \\
\hline
\end{tabular}

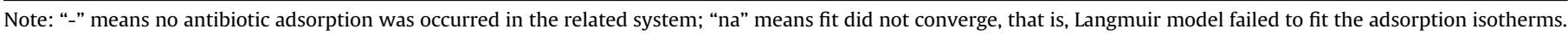

Table 3

Estimated Linear, Freundlich, and Langmuir parameters for antibiotics adsorption on MPs in the seawater system.

\begin{tabular}{|c|c|c|c|c|c|c|c|c|}
\hline \multirow[t]{2}{*}{ MPs } & \multicolumn{2}{|l|}{ Linear } & \multicolumn{3}{|l|}{ Freundlich } & \multicolumn{3}{|l|}{ Langmuir } \\
\hline & $K_{d}\left(\mathrm{~L} \mathrm{~kg}^{-1}\right)$ & $\mathbf{r}^{2}$ & $K_{f}\left(\mathbf{L ~ k g}^{-1}\right)$ & $n$ & $\mathbf{r}^{2}$ & $q_{\max }\left(\mathrm{mg} \mathrm{g}^{-1}\right)$ & $K_{L}\left(\mathrm{~L} \mathrm{mg}^{-1}\right)$ & $\mathbf{r}^{2}$ \\
\hline & TMP & & & & & & & \\
\hline PP & $3.93 \pm 0.944$ & 0.765 & $18.4 \pm 2.65$ & 0.442 & 0.765 & $0.0597 \pm 0.00926$ & 0.551 & 0.917 \\
\hline PS & $7.30 \pm 0.912$ & 0.927 & $13.9 \pm 2.88$ & 0.769 & 0.631 & $0.166 \pm 0.122$ & 0.0969 & 0.724 \\
\hline PVC & $5.45 \pm 0.492$ & 0.961 & $19.0 \pm 2.46$ & 0.303 & 0.419 & $0.0341 \pm 0.0135$ & 1.46 & 0.170 \\
\hline PE & $6.47 \pm 1.02$ & 0.888 & $23.2 \pm 0.861$ & 0.538 & 0.963 & $0.0868 \pm 0.00510$ & 0.469 & 0.989 \\
\hline PA & $\begin{array}{l}5.89 \pm 1.05 \\
S D Z\end{array}$ & 0.938 & $10.0 \pm 1.64$ & 0.560 & 0.992 & $0.130 \pm 0.0320$ & 0.113 & 0.962 \\
\hline PP & $7.13 \pm 0.952$ & 0.948 & $6.48 \pm 8.79$ & 1.02 & 0.744 & na & na & na \\
\hline PS & $6.80 \pm 0.352$ & 0.989 & $5.69 \pm 2.91$ & 1.07 & 0.965 & na & na & na \\
\hline PVC & $5.37 \pm 0.598$ & 0.952 & $0.850 \pm 0.308$ & 1.73 & 0.994 & na & na & na \\
\hline PE & $6.26 \pm 0.630$ & 0.961 & $3.00 \pm 2.98$ & 1.29 & 0.926 & na & na & na \\
\hline PA & $\begin{array}{l}6.56 \pm 0.496 \\
\text { TC }\end{array}$ & 0.983 & $2.53 \pm 0.226$ & 1.38 & 0.999 & na & na & na \\
\hline PA & $4.44 \pm 0.963$ & 0.871 & $12.4 \pm 5.67$ & 0.600 & 0.886 & $0.0878 \pm 0.0192$ & 0.152 & 0.961 \\
\hline
\end{tabular}

Note: "na" means fit did not converge, that is, Langmuir model failed to fit the adsorption isotherms.

accordingly, the anionic speciation of antibiotics in the seawater system were more than in the freshwater system. Meanwhile, all the 5 MPs carried a net negative charge because the $\mathrm{pH}$ in seawater was higher than the PZC of MPs (Table S2). As a result, the enhanced electrostatic repulsions between MPs and antibiotics will reduce sorption level. Earlier study showed that sorption of PFOS on PE, PS, and PVC decreased with increasing pH (Wang et al., 2015). Tizaoui et al. (2017) also reported that increasing $\mathrm{pH}$ of reaction system can reduce endocrine disrupting chemicals (EDCs) adsorption on PA significantly. On the other hand, ionic strength, to a certain extent, could affect the electrostatic interactions since the electrolytes can compete with adsorbate for electrostatic sites (Shen and Gondal, 2017). When ionic strength increased, cations such as $\mathrm{Na}^{+}$and $\mathrm{Ca}^{2+}$ may be attracted electrostatically to the MPs surface. Further, the inorganic exchangeable cations (e.g. $\mathrm{Na}^{+}$) can substitute the hydrogen ions of acidic groups and then inhibit the formation of $\mathrm{H}-$ binding (Aristilde et al., 2010). These findings suggested that adsorption sites may decrease under high ionic strength condition. Therefore, adsorption of the tested antibiotics on MPs decreased at high ionic strength level. This result agreed with previous studies which demonstrated that the adsorption capacities of various antibiotics on different kinds of sorbents (e.g. marine sediments and soils) decreased with increasing of ionic strength (Wang et al., 2010; Xu and Li, 2010; Cao et al., 2015; Li and Zhang, 2017). Our study showed that all the tested antibiotics tend to be adsorbed by MPs in the freshwater system. The increase adsorption extents of antibiotics on MPs in the freshwater system may enhance their bioavailability and accumulation in food chain.

\subsection{Environmental implications}

Antibiotics and MPs are two classes of emerging contaminants 
and have attracted increasing public attention due to their potential toxicity to freshwater and marine ecosystems. Published studies have provided strong evidence that MPs can serve as a vector for the bioaccumulation of toxic chemicals (e.g. POPs and PPCPs) and the combination exhibit higher lethality than MPs themselves (Browne et al., 2013; Rochman et al., 2013; Chua et al., 2014). Although there is yet no available data on the combined effects of MPs and antibiotics, adsorption on MPs may result in the longrange transport of antibiotics and increase their exposure to aquatic ecosystem since antibiotics and MPs are ubiquitous in the aquatic environment and have the similar pollution resources (e.g. domestic wastewater and aquaculture pollution). Furthermore, MPs exposed to the environment may have higher affinity for antibiotics due to the increased specific surface area and polar groups from fragmentation and weathering. Interactions between MPs and antibiotics certainly need to be considered in evaluating the environmental risks associated with the two emerging contaminants.

\section{Conclusion}

The adsorption behaviors of 5 antibiotics on 5 types of microplastic particles were investigated using batch type experiments. Our results showed that adsorption capacities varied among antibiotics, plastic types, and environmental conditions (e.g., ionic strength and $\mathrm{pH}$ ). PA had high affinity for AMX, TC, and CIP in the freshwater system, potentially due to the formation of hydrogen bonding. Adsorption capacities of CIP in the freshwater system were relatively strong related to its cation speciation. All the tested antibiotics exhibited higher amount of adsorption in the freshwater than in seawater. Hydrogen bonding, hydrophobic interaction, van der Waals force, and electrostatic interaction were the main binding mechanisms between antibiotics and MPs. In the future studies, experiments should be performed 1) to investigate adsorption capacities of different speciation of antibiotics (i.e. cation, zwitterion, and anion) on MPs under different $\mathrm{pH} ; 2$ ) to reveal the effects of the major ions (e.g. $\mathrm{Cl}^{-}$, SO3- 4, PO3- 4, $\mathrm{Na}^{+}$) on antibiotics adsorption on MPs; 3 ) to evaluate the release of adsorbed antibiotics from MPs during their transport from river to ocean.

\section{Acknowledgements}

This study was financially supported by National Key R \& D projects (2016YFC1402202) and the Key projects of international cooperation of Chinese Academy of Sciences (KYSB20160003).

\section{Appendix A. Supplementary data}

Supplementary data related to this article can be found at https://doi.org/10.1016/j.envpol.2018.02.050.

\section{References}

Antony, A., Fudianto, R., Cox, S., Leslie, G., 2010. Assessing the oxidative degradation of polyamide reverse osmosis membrane-Accelerated ageing with hypochlorite exposure. J. Membr. Sci. 347, 159-164.

Aristilde, L., Marichal, C., Miehe-Brendle, J., Lanson, B., Charlet, L., 2010. Interactions of oxytetracycline with a smectite clay: a spectroscopic study with molecular simulations. Environ. Sci. Technol. 44, 7839-7845.

Bakir, A., Rowland, S.J., Thompson, R.C., 2012. Competitive sorption of persistent organic pollutants onto microplastics in the marine environment. Mar. Pollut. Bull. 64, 2782-2789.

Bakir, A., Rowland, S.J., Thompson, R.C., 2014a. Enhanced desorption of persistent organic pollutants from microplastics under simulated physiological conditions. Environ. Pollut. 185, 16-23.

Bakir, A., Rowland, S.J., Thompson, R.C., 2014b. Transport of persistent organic pollutants by microplastics in estuarine conditions. Estuar. Coast Shelf Sci. 140, $14-21$.

Batel, A., Linti, F., Scherer, M., Erdinger, L., Braunbeck, T., 2016. Transfer of benzo a pyrene from microplastics to Artemia nauplii and further to zebrafish via a trophic food web experiment: CYP1A induction and visual tracking of persistent organic pollutants. Environ. Toxicol. Chem. 35, 1656-1666.

Brennecke, D., Duarte, B., Paiva, F., Cacador, I., Canning-Clode, J., 2016. Microplastics as vector for heavy metal contamination from the marine environment. Estuar. Coast Shelf Sci. 178, 189-195.

Browne, M.A., Crump, P., Niven, S.J., Teuten, E., Tonkin, A., Galloway, T., Thompson, R., 2011. Accumulation of microplastic on shorelines woldwide: sources and sinks. Environ. Sci. Technol. 45, 9175-9179.

Browne, M.A., Niven, S.J., Galloway, T.S., Rowland, S.J., Thompson, R.C., 2013. Microplastic moves pollutants and additives to eorms, reducing functions linked to health and biodiversity. Curr. Biol. 23, 2388-2392.

Cao, X., Pang, H., Yang, G., 2015. Sorption behaviour of norfloxacin on marine sediments. J. Soils Sediments 15, 1635-1643.

Chua, E.M., Shimeta, J., Nugegoda, D., Morrison, P.D., Clarke, B.O., 2014. Assimilation of polybrominated diphenyl ethers from microplastics by the marine amphipod, allorchestes compressa. Environ. Sci. Technol. 48, 8127-8134.

Ferro-Garcia, M.A., Rivera-Utrilla, J., Bautista-Toledo, I., Moreno-Castilla, C., 1998. Adsorption of humic substances on activated carbon from aqueous solutions and their effect on the removal of $\mathrm{Cr}$ (III) ions. Langmuir 14, 1880-1886.

Fok, L., Cheung, P.K., Tang, G., Li, W.C., 2017. Size distribution of stranded small plastic debris on the coast of Guangdong, South China. Environ. Pollut. 220, 407-412.

Guo, X., Wang, X., Zhou, X., Kong, X., Tao, S., Xing, B., 2012. Sorption of four hydrophobic organic compounds by three chemically distinct polymers: role of chemical and physical composition. Environ. Sci. Technol. 46, 7252-7259.

Hidalgo-Ruz, V., Gutow, L., Thompson, R.C., Thiel, M., 2012. Microplastics in the marine environment: a review of the methods used for identification and quantification. Environ. Sci. Technol. 46, 3060-3075.

Hueffer, T., Hofmann, T., 2016. Sorption of non-polar organic compounds by microsized plastic particles in aqueous solution. Environ. Pollut. 214, 194-201.

Jambeck, J.R., Geyer, R., Wilcox, C., Siegler, T.R., Perryman, M., Andrady, A. Narayan, R., Law, K.L., 2015. Plastic waste inputs from land into the ocean. Science 347, 768-771.

Jiang, L., Hu, X.L., Yin, D.Q., Zhang, H.C., Yu, ZY. 2011. Occurrence, distribution and seasonal variation of antibiotics in the Huangpu River, Shanghai, China. Chemosphere 82, 822-828.

Kanda, M., Nakajima, T., Hayashi, H., Hashimoto, T., Kanai, S., Nagano, C. Matsushima, Y., Tateishi, Y., Yoshikawa, S., Tsuruoka, Y., Sasamoto, T., Takano, I. 2015. Multi-residue determination of polar veterinary drugs in livestock and fishery products by liquid chromatography/tandem mass spectrometry. J. AOAC Int. 98, 230-247.

Kolpin, D.W., Furlong, E.T., Meyer, M.T., Thurman, E.M., Zaugg, S.D., Barber, L.B., Buxton, H.T., 2002. Pharmaceuticals, hormones, and other organic wastewater contaminants in US streams, 1999-2000: a national reconnaissance. Environ. Sci. Technol. 36, 1202-1211.

Le, T.X., Munekage, Y., Kato, S., 2005. Antibiotic resistance in bacteria from shrimp farming in mangrove areas. Sci. Total Environ. 349, 95-105.

Li, J., Zhang, H., 2017. Factors influencing adsorption and desorption of trimethoprim on marine sediments: mechanisms and kinetics. Environ. Sci. Pollut. Res. 24, 21929-21937.

Li, W.H., Shi, Y.L., Gao, L.H., Liu, J.M., Cai, Y.Q., 2012. Occurrence of antibiotics in water, sediments, aquatic plants, and animals from Baiyangdian Lake in North China. Chemosphere 89, 1307-1315.

Lin, J.S., Pan, H.Y., Liu, S.M., Lai, H.T., 2010. Effects of light and microbial activity on the degradation of two fluoroquinolone antibiotics in pond water and sediment. J. Environ. Sci. Heal. B 45, 456-465.

Lunestad, B.T., Samuelsen, O.B., Fjelde, S., Ervik, A., 1995. Photostability of 8 antibacterial agents in seawater. Aquaculture 134, 217-225.

Nel, H.A., Froneman, P.W., 2015. A quantitative analysis of microplastic pollution along the south-eastern coastline of South Africa. Mar. Pollut. Bull. 101, 274-279.

Pils, J.R.V., Laird, D.A., 2007. Sorption of tetracycline and chlortetracycline on K- and Ca-saturated soil clays, humic substances, and clay-humic complexes. Environ. Sci. Technol. 41, 1928-1933.

Plastics-the facts 2015. Available at: http://www.plasticseurope.org/cust/search. aspx? SearchText $=$ production.

Rochman, C.M., Hoh, E., Kurobe, T., The, S.J., 2013. Ingested plastic transfers hazardous chemicals to fish and induces hepatic stress. Sci. Rep. 3, 3263.

Shen, K., Gondal, M.A., 2017. Removal of hazardous Rhodamine dye from water by adsorption onto exhausted coffee ground. J. Saudi Chem. Soc. 21, S120-S127.

Teuten, E.L., Saquing, J.M., Knappe, D.R.U., Barlaz, M.A., Jonsson, S., Bjorn, A., Rowland, S.J., Thompson, R.C., Galloway, T.S., Yamashita, R., Ochi, D. Watanuki, Y., Moore, C., Pham Hung, V., Tana, T.S., Prudente, M., Boonyatumanond, R., Zakaria, M.P., Akkhavong, K., Ogata, Y., Hirai, H., Iwasa, S. Mizukawa, K., Hagino, Y., Imamura, A., Saha, M., Takada, H., 2009. Transport and release of chemicals from plastics to the environment and to wildlife. Philos. Trans. R. Soc. B 364, 2027-2045.

Thompson, R.C., Moore, C.J., vom Saal, F.S., Swan, S.H., 2009. Plastics, the environment and human health: current consensus and future trends. Philos. Trans. R. Soc. B 364, 2153-2166.

Tizaoui, C., Ben Fredj, S., Monser, L., 2017. Polyamide-6 for the removal and recovery of the estrogenic endocrine disruptors estrone, 17 beta-estradiol, 17 alphaethinylestradiol and the oxidation product 2-hydroxyestradiol in water. Chem. Eng. J. 328, 98-105.

Tolls, J., 2001. Sorption of veterinary pharmaceuticals in soils: a review. Environ. Sci. 
Technol. 35, 3397-3406.

Turner, A., Holmes, L., 2011. Occurrence, distribution and characteristics of beached plastic production pellets on the island of Malta (central Mediterranean). Mar. Pollut. Bull. 62, 377-381.

Turner, A., Holmes, L.A., 2015. Adsorption of trace metals by microplastic pellets in fresh water. Environ. Chem. 12, 600-610.

Velzeboer, I., Kwadijk, C.J.A.F., Koelmans, A.A., 2014. Strong sorption of PCBs to nanoplastics, microplastics, carbon nanotubes, and fullerenes. Environ. Sci. Technol. 48, 4869-4876.

Wang, F., Shih, K.M., Li, X.Y., 2015. The partition behavior of perfluorooctanesulfonate (PFOS) and perfluorooctanesulfonamide (FOSA) on microplastics. Chemosphere 119, 841-847.

Wang, J.T., Hu, J., Zhang, S.W., 2010. Studies on the sorption of tetracycline onto clays and marine sediment from seawater. J. Colloid Interface Sci. 349, 578-582.

Watkinson, A.J., Murby, E.J., Kolpin, D.W., Costanzo, S.D., 2009. The occurrence of antibiotics in an urban watershed: from wastewater to drinking water. Sci. Total Environ. 407, 2711-2723.

Wu, C., Zhang, K., Huang, X., Liu, J., 2016. Sorption of pharmaceuticals and personal care products to polyethylene debris. Environ. Sci. Pollut. Res. 23, 8819-8826.
Xu, W.H., Yan, W., Li, X.D., Zou, Y.D., Chen, X.X., Huang, W.X., Miao, L., Zhang, R.J., Zhang G, Zou, S.C. 2013. Antibiotics in riverine runoff of the pearl river delta and pearl river estuary, China: concentrations, mass loading and ecological risks. Environ. Pollut. 182, 402-407.

Xu, X.R., Li, X.Y., 2010. Sorption and desorption of antibiotic tetracycline on marine sediments. Chemosphere 78, 430-436.

Yang, Y., Liu, W., Xu, C., Wei, B., Wang, J., 2017. Antibiotic resistance genes in lakes from middle and lower reaches of the Yangtze River, China: effect of land use and sediment characteristics. Chemosphere 178, 19-25.

Zbyszewski, M., Corcoran, P.L., 2011. Distribution and degradation of fresh water plastic particles along the beaches of Lake Huron, Canada. Water, Air, Soil Pollut. 220, 365-372.

Zhang O. Y Ying G.G, Pan, C.G, Liu, Y.S., Zhao, J.L, 2015. Comprehensive evaluation of antibiotics emission and fate in the river basins of China: source analysis, multimedia modeling, and linkage to bacterial resistance. Environ. Sci. Technol. 49, 6772-6782.

Zhao, S., Zhu, L., Li, D., 2015. Microplastic in three urban estuaries, China. Environ. Pollut. 206, 597-604. 